CPAP. We studied 20 (9 male), ambulatory adult patients with EDAC and/or TBM: mean \pm SD age $60 \pm 13$ years, height 1.67 $\pm 0.86 \mathrm{~m}$, and BMI $34.1 \pm 6.6 \mathrm{~kg} / \mathrm{m}^{2}$. The NRDI was 356 $\pm 182 \mathrm{AU}$ while self-ventilating and reduced when CPAP was applied $(231 \pm 122 \mathrm{AU} ; \mathrm{p}<0.001)$. The 6MWT while on optimal CPAP was increased comparing to self-ventilation and sham CPAP $(296 \pm 112 \mathrm{~m}$ vs $264 \pm 120 \mathrm{~m}$ vs $252 \pm 125 \mathrm{~m}$, respectively; $\mathrm{p}<0.001$ ) (figure 1). The treatment effect between sham and optimal CPAP was $31 \pm 39$ m (95\% CI: 13 to $50 \mathrm{~m}$ ). While on optimal CPAP, 12 patients increased their $6 \mathrm{MWT}$ more than $30 \mathrm{~m}$ compared to self-ventilation (responders). Comparing responders with non-responders, differences were identified for NRDI $(-167 \pm 110 \mathrm{AU}$ vs. -63 $\pm 90 \mathrm{AU}$, respectively; $\mathrm{p}=0.039)$ and $6 \mathrm{MWT}$ while self-ventilating $(203 \pm 94 \mathrm{~m}$ vs. $336 \pm 133 \mathrm{~m}$, respectively; $\mathrm{p}=0.022)$.

In conclusion, CPAP reduces neural respiratory drive and increases exercise capacity in patients with EDAC/TBM. Furthermore, the degree of functional limitation and off-loading of the respiratory muscles on CPAP can identify those likely to have a reduction in neural respiratory drive and enhanced exercise tolerance.

\section{S135 TIMING OF ACIDAEMIA ONSET IN EXACERBATIONS OF COPD REQUIRING ASSISTED VENTILATION AND IN- HOSPITAL MORTALITY}

${ }^{1}$ TM Hartley, ${ }^{1} \mathrm{ND}$ Lane, ${ }^{1} \mathrm{~J}$ Steer, ${ }^{2} \mathrm{C}$ Echevarria, ${ }^{1} \mathrm{SC}$ Bourke. ${ }^{1}$ Northumbria Healthcare NHS Foundation Trust, North Shields, UK; ${ }^{2}$ The Newcastle upon Tyne Hospitals NHS Foundation Trust, Newcastle upon Tyne, UK

\subsection{6/thoraxjnl-2017-210983.141}

Introduction Predicting which patients are likely to benefit from assisted ventilation in exacerbations of COPD (ECOPD) is difficult. Existing prognostic scores did not assess the prognostic value of timing of acidaemia onset relative to admission during development. The 2011 National Chronic Obstructive Pulmonary Disease Resources and Outcomes Project (NCROP) report identified this as a potentially important marker of non-invasive ventilation (NIV) success but further study has been limited. We investigated the relation of timing of respiratory acidaemia to NIV outcomes in ECOPD. Of importance, in both participating hospitals few patients are denied NIV on grounds of assumed futility.

Methods A retrospective cohort of consecutive, unique patients, hospitalised with a primary diagnosis of ECOPD were identified from known cohorts, hospital coding records coding and ventilation service records. Other selection criteria included: age 35 +years, smoking history $10+$ pack years, airflow obstruction on spirometry; received assisted ventilation (either NIV or invasive) for acidaemic respiratory failure; and absence of comorbidity expected to limit survival to $<12$ months (principally metastatic cancer). Population descriptors, ventilation details and outcome data were collected from notes and electronic records.

Results 489 consecutive patients were identified between 30/ $11 / 08$ and $19 / 5 / 13 ; 124$ (25.4\%) died in-hospital. Median time to ABG prompting ventilation was 2 hour $42 \mathrm{~m}$ (IQR 1 hour $2 \mathrm{~m}-15$ hour $28 \mathrm{~m}$ ). Most (94.5\%) received NIV alone, $5.5 \%$ received invasive ventilation (+/-NIV). In patients requiring assisted ventilation within 12 hours of admission, mortality was $18.3 \%(65 / 356)$, compared to $44.3 \%(59 / 133)$ in all those treated after 12 hours $(\mathrm{p}<0.01)$.
Discussion Our study has several strengths including objective confirmation of COPD, capture of consecutive patients and liberal NIV use. Compared to patients with respiratory acideamia on or shortly after admission, later development was associated with progressively higher mortality. 12 and 48 hours were identified as clinically useful thresholds. Of note, lower $\mathrm{pH}$, FEV1 and prior LTOT prescription do not account for worse outcome. Older age, greater comorbidity, frailty (eMRCD5b: requiring help washing and dressing when recently stable), and a strong trend towards increasing pneumonia are associated with later development of acidaemia. Timing of acidaemia should be considered when deciding whether to initiate NIV.

Abstract S135 Table 1 Key population descriptors and inpatient mortality grouped by timing of acidaemia onset

\begin{tabular}{llll}
\hline Time & Up to 12 hours & $12-48$ hours & $>48$ hours \\
\hline $\mathrm{N}$ & 356 & 69 & 64 \\
Age & $71.9(9.9)$ & $73.8(10.0)$ & $76(9.8)$ * \\
FEV1\% & $37.1(15.6)$ & $42.8(18.9) *$ & $38.1(17.4)$ \\
BMI & $24.9(7.5)$ & $24.7(5.9)$ & $22.8(7.2) \dagger$ \\
LTOT & $109(30.6 \%)$ & $18(26.1 \%)$ & $16(25.0 \%)$ \\
eMRCD & $5 a(4-5 a)$ & $5 a(4-5 a)$ & $5 a(4-5 b) \dagger$ \\
eMRCD 5a & $120(33.7 \%)$ & $25(36.2 \%)$ & $19(29.7 \%)$ \\
eMRCD 5b & $63(17.7 \%)$ & $13(18.8 \%)$ & $24(37.5 \%) *$ \\
Charlson Index & $1(1-2)$ & $2(1-3)$ & $2(1-3) *$ \\
Consolidation at NIV & $157(44.1 \%)$ & $38(55.1 \%)$ & $36(56.3 \%)$ \\
pH at NIV & $7.23(0.09)$ & $7.26(0.08) \dagger$ & $7.26(0.08) \dagger$ \\
PCO2 at NIV & $10.3(2.5)$ & $10.0(2.4)$ & $9.3(1.8) *$ \\
Peak Pressure (IPAP) & $20(18-22)$ & $19(17-20)$ & $18(16-20) \dagger$ \\
Inpatient Mortality & $65(18.3 \%)$ & $22(31.9 \%) \dagger$ & $37(57.8 \%) \dagger$ \\
\hline
\end{tabular}

t-test, Mann Whitney $U$ or $\chi^{2}$ test for parametric, non-parametric and categorical data respectively.

* $p<0.05 ; \uparrow p<0.01$ : compared to "Up to 12 hours group"

\section{S136 LUNG PROTECTIVE MECHANICAL VENTILATION FOR ACUTE RESPIRATORY FAILURE IS NOT BEING IMPLEMENTED IN UK CLINICAL PRACTICE}

${ }^{1} \mathrm{R}$ Samanta, ${ }^{1} \mathrm{~A}$ Dixit, ${ }^{2} \mathrm{~S}$ Harris, ${ }^{2} \mathrm{NS}$ MacCallum, ${ }^{2} \mathrm{DA}$ Brearley, ${ }^{3} \mathrm{PJ}$ Watkinson, ${ }^{4} \mathrm{~A}$ Jones, ${ }^{5} \mathrm{~S}$ Ashworth, ${ }^{4} \mathrm{R}$ Beale, ${ }^{5} \mathrm{~S} J$ Brett, ${ }^{3} \mathrm{JD}$ Young, ${ }^{2} \mathrm{M}$ Singer, ${ }^{1} \mathrm{C}$ Summers, ${ }^{1} \mathrm{~A}$ Ercole. ${ }^{1} \mathrm{Dept}$ of Medicine, University of Cambridge School of Clinical Medicine, Cambridge, UK; ${ }^{2}$ Bloomsbury Institute of Intensive Care Medicine, University College London, London, UK; ${ }^{3}$ Nuffield Department of Clinical Neurosciences, University of Oxford, Oxford, UK; ${ }^{4}$ Department of Intensive Care, Guy's and St Thomas' NHS Foundation Trust, London, UK; ${ }^{5}$ Centre for Perioperative Medicine and Critical Care Research, Imperial College Healthcare NHS Trust, London, UK

\subsection{6/thoraxjnl-2017-210983.142}

Introduction The benefits of lung protective ventilation have been replicated in multiple trials. ${ }^{1,2}$ However, we suspected that adherence to this standard of care remained poor. Using the NIHR critical care Health Informatics Collaborative (ccHIC) database, we analysed data from 11 teaching hospital intensive care units (22 524 patient episodes) to investigate real-world clinical practice.

Methods 1248 patient episodes, where ventilation was continued for $\geq 48$ hours, with 232,600 hours of concurrent mechanical ventilation and blood gas data were identified as suitable for analysis. Short gaps in ventilation $(<6$ hours) were imputed based on the median of nearest known values, and 
only the single longest period of ventilation from each patient episode was analysed.

Results The median tidal volume received by patients was 7.3 $\mathrm{ml} / \mathrm{kg}^{-1}$ PBW (IQR:5.7-8.8). Female patients, especially those with higher BMI $\left(\geq 30 \mathrm{kgm}^{-2}\right)$ consistently received higher tidal volumes than males. Patients with severe respiratory failure $\left(\mathrm{PaO}_{2}: \mathrm{FiO}_{2}<13 \mathrm{kPa}\right)$ received a median tidal volume of $7.1 \mathrm{ml} / \mathrm{kg}^{-1}$ PBW, and had 71\% ICU mortality (Table 1). Patients with respiratory failure sufficient to qualify for recruitment into recent clinical trials $\left(\mathrm{PaO}_{2}: \mathrm{FiO}_{2}<20 \mathrm{kPa}\right.$ with PEEP $\geq 5 \mathrm{~cm} / \mathrm{H}_{2} 0$ ), who were exposed to tidal volumes $\geq 12 \mathrm{ml} / \mathrm{kg}^{-1}$ PBW for longer than two hours had significantly increased risk of ICU mortality (odds ratio=2.89 [1.257.2]; $\mathrm{p}=0.007)$; This was not observed for patients with $\mathrm{PaO}_{2}: \mathrm{FiO}_{2} \geq 40 \mathrm{kPa}$ (odds ratio=0.95 [0.58-1.56], $\mathrm{p}=0.91$ ).

Conclusions More than 15 years after the ARMA study ${ }^{1}$ demonstrated a mortality benefit from lung protective ventilation, we are still not implementing $6 \mathrm{ml} / \mathrm{kg}^{-1} \mathrm{PBW}$ ventilation into clinical practice, and are exposing even patients with a severe respiratory failure $\left(\mathrm{PaO}_{2}: \mathrm{FiO}_{2}<13 \mathrm{kPa}\right)$ to higher than recommended tidal volumes, with females and higher BMI patients at particular risk. We have also demonstrated that failure to institute lung protective ventilation in patients with $\mathrm{a} \mathrm{PaO}_{2}$ : $\mathrm{FiO}_{2}<20 \mathrm{kPa}$ leads to increased ICU mortality, which is not present in patients with $\mathrm{PaO}_{2}: \mathrm{FiO}_{2} \geq 40 \mathrm{kPa}$.

\section{REFERENCES}

1. ARDS Network. Ventilation with lower tidal volumes as compared with traditional tidal volumes for ALI and ARDS. NEJM 2000;342:1301-1308.

2. Futier $\mathrm{E}$ et al. A trial of intraoperative low tidal volume ventilation in abdominal surgery. NEJM 2013;369:428-437.

\begin{tabular}{llllll} 
Abstract S136 Table 1 & \multicolumn{5}{c}{ Patient characteristics, outcomes and } \\
mechanical ventilation stratified by severity of respiratory failure
\end{tabular}

APACHE II=Acute Physiology and Chronic Health Score II, PBW=predicted body weight, $P E E P=$ positive end expiratory pressure 


\section{Complications of TB and extra-pulmonary TB}

P1
ACCESS TO BEDAQUILINE AND DELAMANID IN
ENGLAND FOR TREATMENT OF DRUG RESISTANT
MYCOBACTERIAL DISEASE - RESULTS OF A TB SAG
SURVEY

${ }^{1} \mathrm{GC}$ Hagan, ${ }^{2} \mathrm{M}$ Dedicoat, ${ }^{3} \mathrm{G}$ Bothamley. ${ }^{1}$ Sandwell and West Birmingham NHS Trust, Birmingham, UK; ${ }^{2}$ Heart of England NHS Foundation Trust, Birmingham, UK; ${ }^{3}$ Homerton University Hospital NHS Foundation Trust, London, UK

\subsection{6/thoraxjnl-2017-210983.143}

Introduction and objectives Bedaquiline and delamanid were centrally commissioned by NHS England for management of MDR and XDR-TB, within specified criteria (including age 16-65, pulmonary disease, discussion in BTS MDR-TB forum and six months usage) in Aug 2015. We sought to determine ease of availability, obstacles faced and off licence use by prescribing centres.

Methods An electronic survey was sent to the leads or nominated deputy of MDR-TB centres in England, and the responses analysed using the Surveymonkey web tool.

Results Response rate was $64 \%(18 / 28)$. Of the respondents, 8 centres (44\%) had not used the drugs since Aug 2015. Of the remainder, indications in all cases were either drug resistance (90\% of centres) or intolerance (70\% of centres). Intolerance was usually hearing loss from second line injectable agents and tendonitis from fluoroquinolones; a minority of patients also could not tolerate prolonged linezolid. $90 \%$ of cases had been discussed in the BTS MDR-TB forum; the exception was a case of non tuberculous mycobacterial(NTM) disease $(M$. abscessus) which was discussed with other NTM experts. There was minimal delay ( $<2$ weeks) between the MDR-TB forum decision to use the drugs and NHS England approval when used for licenced indications; one delay occurred when requesting an extension beyond 6 months (7 weeks delay). There was minimal delay ( $<2$ weeks) between NHS England approval and the patient actually receiving the drug. Both drugs were used in the same patient by two centres (20\%). The drugs had been used 'off licence' by 6/10 centres. Details in Table 1. Free text responses highlighted difficulty in obtaining the outcome of individualised funding request decisions, difficulty obtaining funding for children (being paid for by the children's hospital in one case), and two rejections of the use in NTM disease.

Conclusions Access to bedaquiline and delamanid within licenced indications seems to have minimal delay. Difficulties may arise when the drug needs to be used for $\geq 6$ months. Problems are also reported with funding in children. There is emerging evidence of benefit in difficult NTM disease; this is an unlicensed indication that may expand in the future. Consideration may need to be given to a forum for difficult NTM disease.
Abstract P1 Table 1 Off licence use of bedaquiline and delamanid by MDR-TB centres

\begin{tabular}{|c|c|c|}
\hline $\begin{array}{l}\text { Reason for off- } \\
\text { licence use of } \\
\text { bedaquiline/ } \\
\text { delamanid }\end{array}$ & $\begin{array}{l}\% \text { of centres (note each } \\
\text { centre may have more than } \\
\text { one off licence usage) }\end{array}$ & Details \\
\hline $\begin{array}{l}\text { Duration longer than } \\
6 \text { months }\end{array}$ & $30 \%$ & $\begin{array}{l}\text { All cases pulmonary XDR with } \\
\text { large burden of disease and/or } \\
\text { limited treatment options }\end{array}$ \\
\hline $\begin{array}{l}\text { Extra-pulmonary } \\
\text { MDR/XDR disease }\end{array}$ & $20 \%$ & Lymph node TB \\
\hline NTM disease & $20 \%$ & $\begin{array}{l}\text { M chimaera sternal wound } \\
\text { infection (multiple drug } \\
\text { intolerances) and M abscessus } \\
\text { extensive pulmonary disease } \\
\text { (funding declined by NHS England } \\
\text { in both cases, funded by hospital } \\
\text { in one case and appeal for } \\
\text { compassionate use in the other) }\end{array}$ \\
\hline $\begin{array}{l}\text { Drug intolerance in } \\
\text { fully sensitive } \\
\text { disease }\end{array}$ & $10 \%$ & $\begin{array}{l}\text { Toxic epidermal necrolysis to first } \\
\text { line agents }\end{array}$ \\
\hline
\end{tabular}

\section{P2 USING AN APP TO DETECT EARLY ETHAMBUTOL TOXICITY}

E Batalla-Duran, R Unsworth. Royal Devon and Exeter Hospital, Exeter, UK

\subsection{6/thoraxjnl-2017-210983.144}

Aim Ethambutol is one of the first-line drugs used to treat tuberculosis (TB) but its side effects include optic neuropathy, causing sight loss and changes in colour-vision. Early detection can mean any toxicity is reversible. Careful monitoring of sight is therefore required in patients taking ethambutol. After a patient irreversibly lost his sight from ethambutol toxicity and a successful claim was made against the hospital, more robust methods of monitoring eyesight were needed in patients taking ethambutol.

Method Currently in our department, all patients being started on ethambutol are referred to the ophthalmology department for baseline eye testing of visual acuity and colour vision. They are tested again at 4-6 months if they remain on ethambutol past 2 months. In between this, we previously relied on the patient reporting any change in vision to the TB team who would then arrange additional formal testing. To improve monitoring, we purchased two apps- a Munsell D15 Colour Vision Test and a LogMAR acuity test- to be used on an iPad. Four members of clinic staff were trained to use the apps. All patients on prolonged ethambutol now have their vision tested at all TB clinic appointments (usually monthly). 